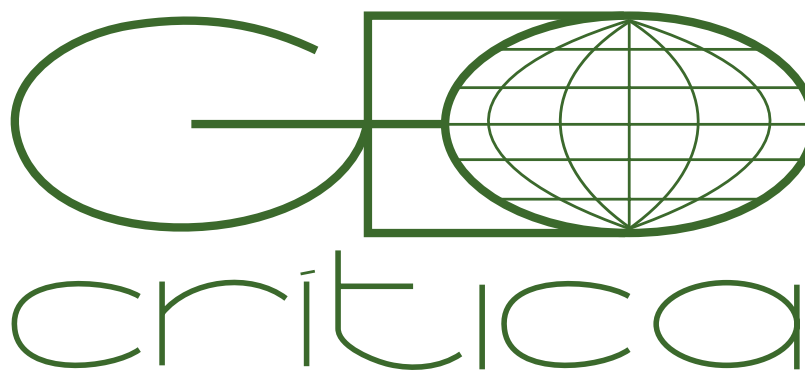

\section{Scripta Nova}

Revista Electrónica de Geografía y Ciencias Sociales Universidad de Barcelona

1 de enero de 2017

\title{
CONSECUENCIAS SOCIALES DEL MODELO ECONÓMICO BASADO EN EL CRÉDITO. GEOGRAFÍA DE LAS EJECUCIONES HIPOTECARIAS EN MENORCA*
}

\author{
SòniaVives-Miró \\ Departamento de Xeografia. Universidade de Santiago de Compostela \\ so.vives@gmail.com \\ Onofre Rullan \\ Departament de Geografia. Universitat de les Illes Balears \\ orullan@uib.es \\ Jesús M. González Pérez \\ Departament de Geografia. Universitat de les Illes Balears \\ jesus.gonzalez@uib.es \\ Recibido: 15 de marzo de 2016. Aceptado: 25 de junio de 2016.
}

*El presente trabajo ha sido posible gracias a una Beca de investigación del Institut Menorquí d'Estudis, convocatoria 2014 y al proyecto de investigación del Plan Nacional de I+D+I del Ministerio de Economía y Competitividad: "Crisis y vulnerabilidad en ciudades insulares españolas: transformaciones en los espacios de reproducción social" (CSO2015-68738-P).
Resumen. Consecuencias sociales deo modelo económico basado en el crédito. Geografía de las ejecuciones hipotecarias en Menorca

El proceso de perdida de la vivienda que está sacudiendo a parte de la población con consecuencia de ejecuciones hipotecarias se entiende como parte de una estrategia de desposesión y cercamiento que la literatura al uso ha llamado new urban enclosures. Para analizar el proceso se presenta el caso de Menorca donde se analizan las ejecuciones hipotecarias con diferentes grados de resolución geográfica, llegando a la escala de dirección postal. El análisis se vincula a la política crediticia que alimentó la burbuja y con la geografía de los diferentes estatus sociales de la isla. Los resultados muestran cómo las ciudades, y en ellas las zonas de estatus social menor, es donde el proceso de desposesiones de viviendas por ejecuciones hipotecarias ha sido mayor, mientras que en las zonas rurales con zonas donde reside población con estatus social más heterogéneo el impacto de la crisis ha sido menor.

Palabras clave: Ejecuciones hipotecarias, burbuja inmobiliaria, Menorca, Maó.

\begin{abstract}
Social consequences of the economic model based on credit. Geography of foreclosures in Menorca

The process of housing losing that is shaking part of the population as a consequence of foreclosures it is seen as part of a strategy of home dispossession that literature called new urban enclosures. To analyze the process the example of Menorca is presented. It is shown trough varying degrees of geographical resolution of the foreclosures, reaching the level of street. The analysis is linked to the credit policy that fueled the bubble and to the geography of different social status of the island.The results show how the cities, and the areas of lower social status, is where the process of home dispossession by foreclosures was bigger, while in rural areas where most heterogeneous population lives, the impact of social status the crisis has been less.
\end{abstract}

Keywords: foreclosures, housing bubble, Menorca, Mahon. 
En las Islas Baleares, entre 2001 y 2014, han tenido lugar 18.718 ejecuciones hipotecarias, de las que 15.447 (el 82,5\%) se han producido a partir de 2008, desde que estalló la burbuja inmobiliaria. De estas ejecuciones, 15.745 (el 84,11\%) se produjeron en Mallorca, 1.501 (el 8\%) en Menorca y 1.472 (el 7,86\%) en Ibiza (figura 1).

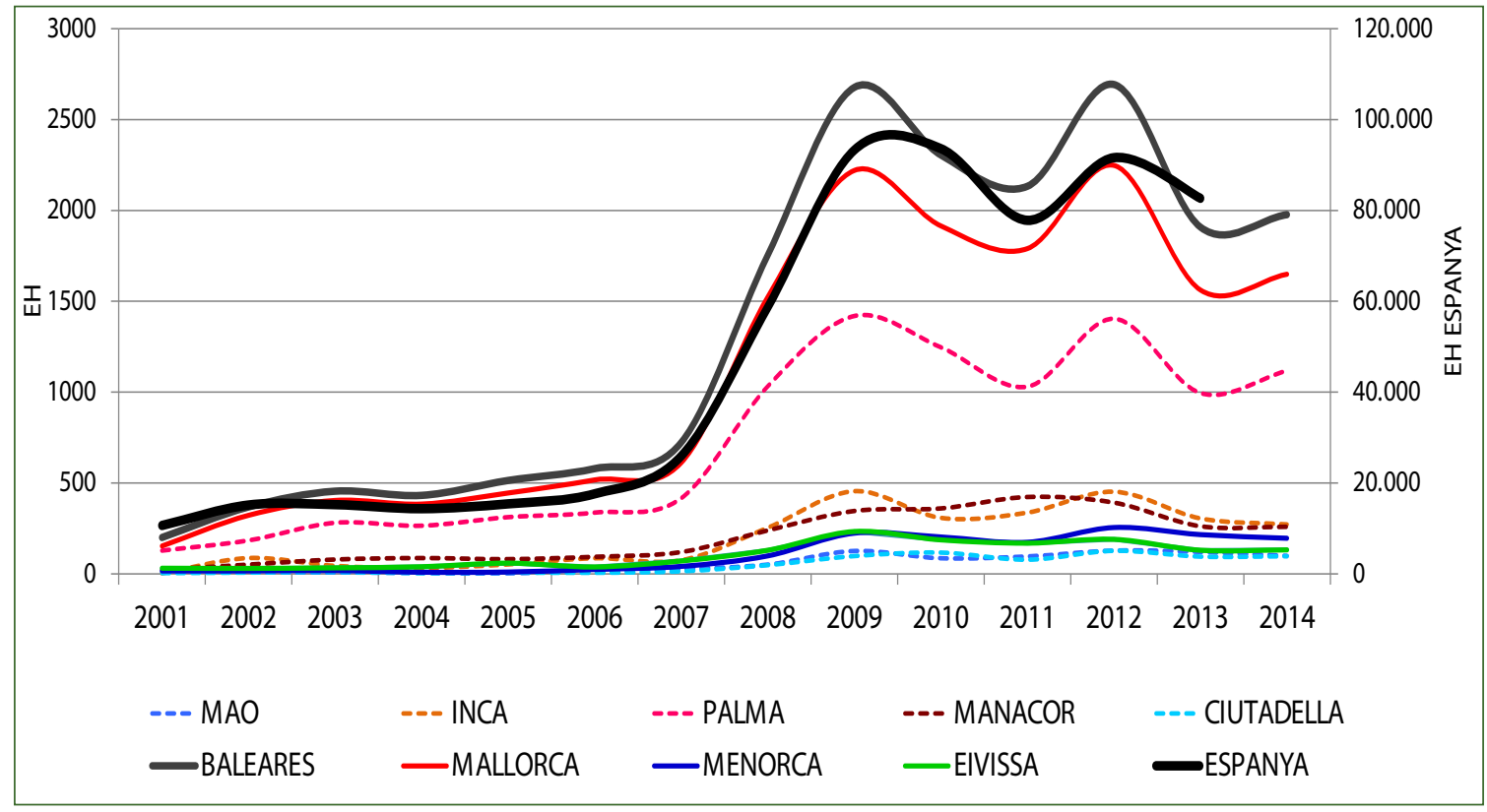

Figura1. Ejecuciones hipotecarias en las Islas Baleares(2001-2014)

Fuente: elaboración propia a partir de datos del Consejo General del Poder Judicial ${ }^{1}$

En el caso de Menorca, de las 1.501 ejecuciones, 789 han tenido lugar en el partido judicial de Maó y 712 en el de Ciutadella (figura 2). En Menorca, el incremento de las ejecuciones hipotecarias desde que comenzó la crisis respecto a las de antes es del 91\%, mientras que en Mallorca es del $81 \%$ y en Ibiza del 79,5\%. Es decir, que el impacto de la crisis en Menorca ha sido proporcionalmente más elevado que en el resto del archipiélago. De hecho, a pesar de que Palma deviene (con 7.127 ejecuciones entre 2008 y 2013) el séptimo de los 431 partidos judiciales de España con más ejecuciones, sólo superado por Madrid, Sevilla, Barcelona, Valencia, Orihuela y Murcia, el partido judicial de Ciutadella obtiene la tercera tasa de crecimiento más alta de España entre 2002-2007 y desde 2008 hasta 2013 (1.072,92\%), seguida de Fuengirola $(1.129,02 \%)$ y Vera $(1.140,10 \%)$. Estos tres partidos judiciales han multiplicado más de diez veces el número de ejecuciones hipotecarias respecto a las que presentaban antes de la crisis. ${ }^{2}$.

La relación entre el volumen de crédito concedido y las ejecuciones hipotecarias es más que evidente en toda España, en el caso de Menorca mientras en 2006 se concedían 4200 hipotecas para viviendas y tan solo se llevaban a cabo 24 ejecuciones

1 http://www.poderjudicial.es/cgpj/es/Temas/Estadistica-Judicial/Base-de-datos-de-la-estadistica-judicial-PC-AXIS-/ [visita 25/02/2016]

2 Méndez, Abad, Plaza, 2014: 24. 
hipotecarias, siete años más tarde, en 2013, las hipotecas concedidas habían disminuido a 550 y las ejecuciones hipotecarias habían aumentado a $216^{3}$. El análisis estadístico de las series de hipotecas y ejecuciones hipotecarias presenta un marcado coeficiente de correlación de -0,84.

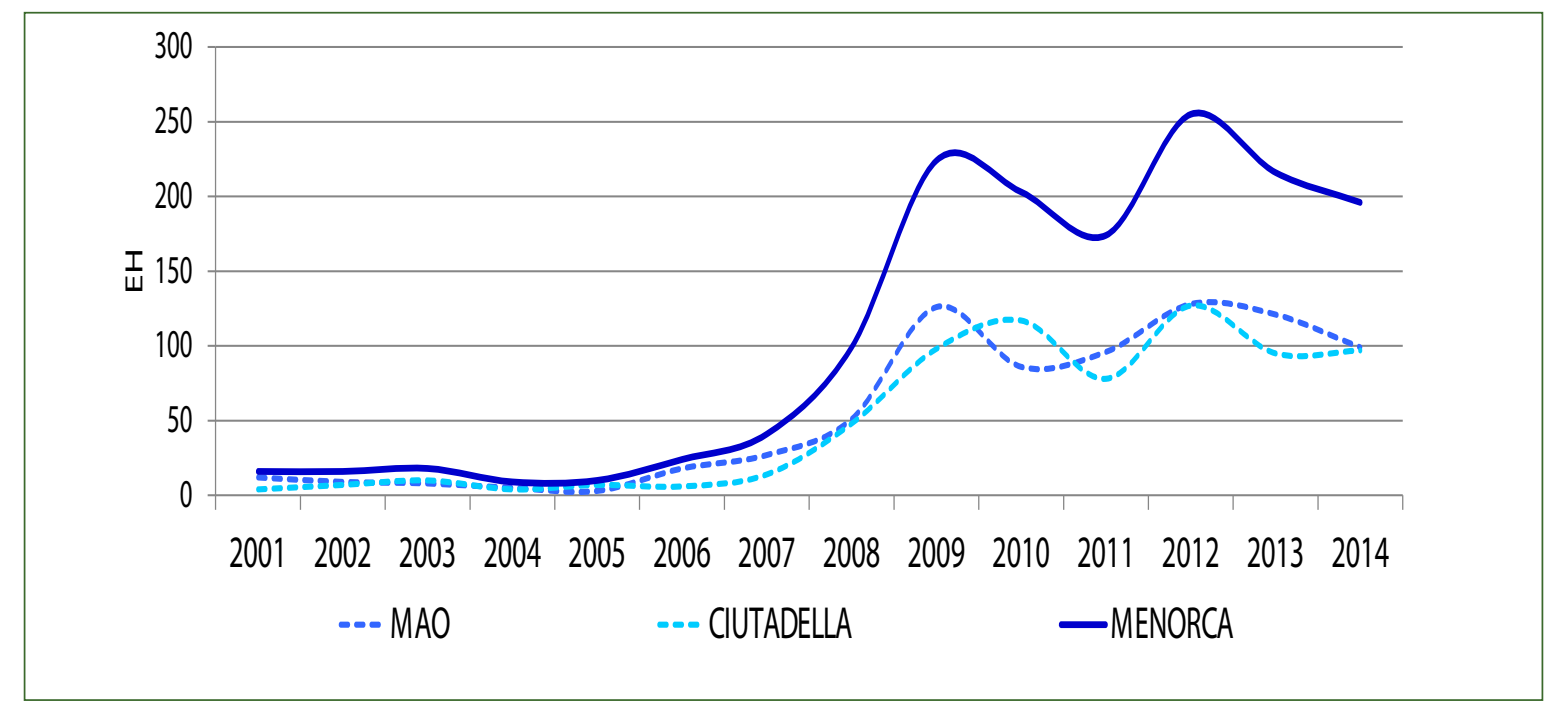

Figura 2. Evolución de las ejecuciones hipotecarias en Menorca y sus partidos judiciales entre 1995 y 2013

Fuente: elaboración propia a partir de datos del Consejo General del Poder Judicial

La gravedad de la desposesión de vivienda y las implicaciones socio-urbanas que genera hacen necesario profundizar en el análisis del fenómeno en la isla. En este contexto, el objetivo principal de este artículo es el de estudiar la realidad socio-urbana que presenta Menorca desde que comenzó la crisis inmobiliaria hasta la actualidad, evaluando las transformaciones socio-urbanas vinculadas a la desposesión de vivienda que han tenido lugar en este periodo y su distribución geográfica.

En este sentido, el trabajo pretende hacer una aportación analítica urbana que contribuya a los estudios sobre el territorio menorquín los que, hasta ahora, han tenido mayoritariamente un alcance más bien territorial que urbano. De este modo, como objetivos específicos, este trabajo persigue, por un lado, realizar un análisis de las condiciones sociourbanas de las distintas zonas urbanas sometidas a ejecuciones hipotecarias y, por otro, llevar a cabo un análisis espacial tanto de las condiciones socio-urbanas como de la ejecuciones hipotecarias.

Para ello, el texto se estructura en cuatro apartados principales. En primer lugar, se hace una contextualización sobre la crisis, los desahucios y las ejecuciones hipotecarias como manifestaciones de los procesos de acumulación por desposesión en el contexto global y español. En segundo lugar, se expone la metodología y las fuentes que se han utilizado para la elaboración de este trabajo. En tercer lugar, analiza la

3 Consejo General del Poder Judicialhttp://www.poderjudicial.es/cgpj/es/Temas/Estadistica-Judicial/Basede-datos-de-la-estadistica-judicial--PC-AXIS-/ y datos IBESTAThttp://www.ibestat.cat/ibestat/inici [visita 25/02/2016] 
realidad socio-urbana de Menorca en el periodo 1995-2007 y, finalmente, se aterriza en el análisis de la geografía de las ejecuciones hipotecarias de Menorca, detallando el análisis en la ciudad de Maó.

\section{Vivienda y desahucios en la literatura científica}

Los trabajos sobre vivienda, su vinculación con el modelo inmobiliario y el corolario de la oleada de desahucios con que se ha cerrado el último ciclo expansivo son muy abundantes tanto en el campo de la Geografía como, y fundamentalmente, en Economía y Sociología urbanas. A continuación procedemos a una revisión de los principales trabajos al respecto que nos permitan situar y contextualizar nuestro trabajo.

\section{Crisis y desposesión de la vivienda}

El estallido de la burbuja inmobiliaria en 2008 concluyó de forma abrupta el denominado "segundo milagro español". Un modelo fundamentado en la deuda, la revalorización inmobiliaria y la desindustrialización. Durante las décadas de 1990 y 2000, la mayoría de los expertos en el estudio de la ciudad se centraron en explicar las graves consecuencias territoriales y ambientales del modelo económico y urbano por el que habían apostado las ciudades españolas. Es decir, mostraron más atención por explicar la construcción física y social de la ciudad que su destrucción como consecuencia del desmoronamiento del modelo. En los años de crisis, el estudio de los impactos socio-urbanos está adquiriendo un nuevo protagonismo. En este contexto, el estudio de los desahucios y la desposesión de la vivienda es, por un lado, una de las consecuencias de la crisis económica, la explosión de la burbuja inmobiliaria y de la aplicación de las denominadas políticas urbanas poscrisis de fuerte componente neoliberal y, por otro, una variable fundamental en los análisis de vulnerabilidad y desigualdad urbana.

Las ejecuciones hipotecarias y los desahucios son una manifestación de los cercamientos $^{4}$ de la vivienda articulado mediante la financiarización del entorno construido. La teoría urbana crítica ${ }^{5}$ ha analizado los procesos de producción de desigualdad urbana bajo el neoliberalismo a través de diferentes conceptos: gentrificación ${ }^{6}$, empresarialismo urbano ${ }^{7}$, financiarización de la vida cotidiana ${ }^{8}$, privatización del espacio público ${ }^{9}$ y los nuevos cercamientos urbanos $^{10}$. La literatura marxista ge-

4 Traducción del inglés: enclosure

5 Brenner et al, 2012.

6 Smith 1996; Lees y Ley 2008; Lees, Stater y Wlyly, 2008.

7 Harvey 1989; González Ceballos, 2007; Brenner y Theodore 2002; Peck y Tickell 2002.

8 Kaika y Ruggiero, 2013.

9 Hodkinson, 2013.

10 Midnight Notes Collective 1990. 
neralmente se refiere a los cercamientos históricos como una forma de acumulación primitiva ${ }^{11}$, es decir como una manera de separación entre los productores y la tierra o los medios de producción. La crisis del fordismo en la década de 1970 dio inicio a una nueva etapa para el desarrollo de nuevos cercamientos, con elemento diferentes a los conocidos hasta entonces. Así, a través de la reestructuración del sistema de acumulación capitalista ${ }^{12}$, estos no sólo se caracterizan por la privatización de los medios de producción, sino también por la erosión progresiva de un conjunto de garantías relacionadas con la reproducción social ${ }^{13}$. Actualmente, el proceso de desposesión en la esfera de la reproducción social en los países del sur de Europa tiene lugar en aquellos servicios y derechos ampliamente adquiridos con el desarrollo del Estado del bienestar, entre los que destacan la educación, salud, servicios sociales y vivienda.

La bibliografía científica sitúa la financiarización de la vivienda y el entorno construido como parte de los estudios más genéricos sobre la financiarización ${ }^{14}$. El punto de contacto entre ambos se encuentra en la conversión de la tierra en un activo financiero ${ }^{15}$. Este proceso se materializa a través de procesos como la titulización hipotecaria, que ha tenido una influencia básica para la constitución de las hipotecas inmobiliarias (Residential Mortgage Backed Securities) ${ }^{16}$. Aunque no es la única causa, la revalorización de la propiedad y la burbuja inmobiliaria están directamente relacionadas con este fenómeno. Estas revalorizaciones pueden ser entendidas como un primer paso para la desposesión de viviendas, fundamentalmente si los salarios disminuyen o estos no mantienen el ritmo de crecimiento del precio de la vivienda. Así el préstamo hipotecario pasa a ser la condición necesaria para el acceso a la propiedad de la vivienda ${ }^{17}$.

Pues bien, el denominado "modelo español"18 durante el ciclo 1995-2008 se basó en gran medida en la acumulación a través del entorno construido mediante su continua revalorización. Esto explica que una de las principales consecuencias de la crisis sea la pérdida de vivienda. Desde el comienzo de la crisis, se han registrado más de 400.000 ejecuciones hipotecarias ${ }^{19}$. Los datos sobre el número de desahucios son poco precisos ${ }^{20}$. En definitiva, este artículo se sitúa en el campo de los cercamientos producidos por el proceso de financiarización de la vivienda, entendida como una dinámica de acumulación desarrollada durante el actual ciclo expansivo del capitalismo. En este contexto, se inscriben las desposesiones mediante ejecuciones hipotecarias y los desahucios de inquilinos.

11 Marx 1990 [1864].

12 Midnight Notes Collective 1990.

13 López y Rodríguez, 2010, 2011.

14 Aalbers, 2008, 2009a, 2009b, Christopher, 2011; Dymski, 2009; Gotham, 2006, 2009; Rutland, 2010; Wainwright, 2009; Newman, 2009.

15 Harvey, 1982; Krippner, 2005; Christophers, 2011; Charnock, Purcell y Ribera-Fumaz, 2014.

16 Aalbers, 2008.

17 López y Rodríguez, 2010.

18 López y Rodríguez, 2011.

19 Méndez, Abad y Plaza, 2014.

20 Human Rights Watch, 2014. 


\section{Crisis, desahucios y ejecuciones hipotecarias}

La mayor parte de la literatura sobre financiarización de la vivienda estudia el proceso del capital, pero no profundiza en el fenómeno de la desposesión. La atención de la bibliografía científica es muy desigual, alcanzando gran desarrollo en Estados Unidos, debido a una combinación de variables. Las graves consecuencias de su burbuja inmobiliaria adquieren especial gravedad en un país con un deficiente sistema de protección social e importantes problemas de desigualdad urbana, relacionada con los ingresos y la pertenencia a grupos étnicos minoritarios y/o segregados. En Estados Unidos, una parte importante de la bibliografía sobre ejecuciones hipotecarias vincula a estas con la flexibilización de los mercados hipotecarios o de alto riesgo (subprime), que es habitualmente citada como la principal causa de la crisis hipotecaria. Por lo tanto, esta crisis es el resultado de la desregulación de los mercados financieros y la promoción de la propiedad de la vivienda. Estas prácticas de préstamos de alto riesgo conllevan la aparición de nuevas geografías de la deuda y del riesgo que, a su vez, se superponen a otro tipo de procesos urbanos que suceden en barrios de bajos ingresos discriminados por la raza ${ }^{21}$ o la desigualdad racial ${ }^{22}$. Este último autor analiza como la crisis hipotecaria ha desestabilizado desproporcionadamente a las minorías y los hogares de bajos ingresos, sobre todo cuando al frente de los mismos están mujeres afroamericanas. En una línea similar, otros autores ${ }^{23}$ analizan la distribución espacial de la deuda de los hogares en las ciudades canadienses y los vínculos que guarda con inmigración y raza.

En Europa, tal y como lo constatan algunos autores ${ }^{24}$, la literatura científica sobre desalojos y ejecución hipotecaria es menos numerosa. Probablemente, un sistema de protección social más desarrollado característico de estados del bienestar, que incluye políticas sociales y de vivienda, ha contribuido a soportar mejor los efectos de la crisis y reducir los niveles de vulnerabilidad urbana. Entre las publicaciones más interesantes, destacan los trabajos que investigan las estrategias nacionales

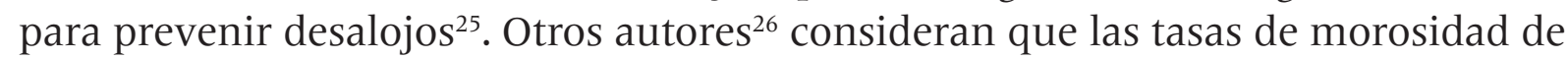
las hipotecas están relacionadas con la excesiva dependencia de los mercados de vivienda de Estados Unidos y determinados países europeos, sobre todo Irlanda y España.

En España, los análisis sobre las causas de la segregación socio-urbana y la dificultad de acceso a la vivienda han emergido durante los años de la burbuja inmobiliaria. No obstante, se echan en falta trabajos que pongan el acento en los desahucios como una consecuencia de las políticas financiero-inmobiliarias desarrolladas durante el ciclo expansivo (1995-2007). Los análisis son abordados desde dos pun-

21 Crump et al, 2008.

22 Fields, 2015.

23 Walks, 2013.

24 Stenberg, Doorn y Gerull, 2011.

25 Gerull, 2014.

26 Moore, Rodríguez-Vives y Saca-Saca, 2013. 
tos de vista. Por un lado, la publicación de artículos periodísticos que alertan a la población de la gravedad del fenómeno, informando de casos particulares y sólo en ocasiones reproduciendo alguna estadística oficial o realizando análisis globales. Por otro, trabajos desde una perspectiva profesional y, en menos ocasiones, científica. Entre estos destacan las aproximaciones desde el punto de vista del derecho ${ }^{27}$, la economía ${ }^{28}$, los movimientos sociales ${ }^{29}$ e incluso las recomendaciones del Defensor del Pueblo ${ }^{30}$. Desde un punto de vista geográfico, el estudio de referencia es el dirigido per Ricardo Méndez ${ }^{31}$. Los datos y análisis se presentan a una escala estatal (2008-2013) con una resolución de partido judicial. Entre otras conclusiones, resulta especialmente interesante la distinción que se realiza entre una fase inicial (2008-2010), donde las políticas keynesianas prevalecen y donde las ejecuciones se centran en el litoral mediterráneo y Madrid; y una segunda etapa (2011-2013), caracterizada por el impulso de políticas neoliberales, donde las ejecuciones hipotecarias se expanden incorporando ciudades medias del sistema urbano. Sin embargo, son poco importantes los trabajos que integren análisis territoriales a escala intraurbana (calles, secciones censales o barrios) y temporales, y que estudien la evolución en los años de burbuja inmobiliaria y crisis. La principal causa puede ser que las estadísticas oficiales presentadas por el Consejo General del Poder Judicial, principal organismo encargado de recoger y publicar esta información, presenta los datos agrupados para los 431 partidos judiciales y no facilite información más detallada geográficamente. Asimismo, el difícil acceso a las fuentes oficiales es probablemente una de las causas por las que el Observatorio de Vulnerabilidad de España no incluye la problemática de los desahucios en su Atlas de Vulnerabilidad. Aun así, hay algunos intentos de descender en la escala con el objetivo de cartografiar y evaluar los impactos que las ejecuciones producen en la ciudad. Por un lado están los trabajos que estudian la distribución de las ejecuciones hipotecarias en Palma a partir de la explotación de los datos oficiales extraídos de los juzgados de primera instancia del municipio ${ }^{32}$. Por otra parte se ha cartografiado el fenómeno en algunas ciudades de Cataluña a escala intraurbanaa partir de los datos proporcionados por las webs de las inmobiliarias adscritas a los bancos ${ }^{33}$. Existe también un trabajo ${ }^{34}$ que, además de cartografiar la información a escala de partido judicial, se ha aproximado al tema con la mapificación (a nivel de dirección postal) de las intervenciones de la PAH (campaña "Stop Desahucios") en Madrid.

Finalmente, la literatura científica sobre desahucios en las Illes Balears es poco importante. Desde la geografía destacamos los dos artículos ya citados sobre Palma con resolución a escala intraurbana. No hay referencias sobre Menorca. Aunque los

27 Rodríguez, 2014

28 Cano y Etxezarreta, 2014; Etxezarreta et al 2012; Cano et al 2013.

29 ColauyAlemany, 2012; Human Rights Watch, 2014; Navarro, 2012; Valiño, 2013.

30 Defensor del Pueblo, 2013.

31 Méndez, Abad y Plaza, 2014.

32 Vives y Rullan, 2014 y Vives; González y Rullan, 2015.

33 Gutiérrez y Delclós, 2015.

34 Obeso, 2014. 
estudios urbanos sobre las ciudades menorquinas han sido importantes ${ }^{35}$, no hay bibliografía que aborde estas temáticas o se aproximen a problemáticas de vulnerabilidad social o desigualdad urbana.

En definitiva, muchas disciplinas estudian la burbuja financiero-inmobiliaria que caracterizó parte de las décadas de 1990 y 2000. A principios de la década de 2010, la gravedad de la crisis económica inauguró un nuevo escenario que está produciendo nuevas transformaciones socio-urbanas. Por el mismo componente de esta crisis y de las políticas de recortes de raíz neoliberal, estos cambios afectan de manera especial a aquellos países especializados en el binomio financiero-inmobiliario y, de forma particular, a los espacios urbanos y los territorios turísticos. La crisis está suponiendo un incremento de las diferencias entre una mayoría creciente de espacios en crisis y una minoría de espacios elitizados. En este contexto, una de las consecuencias más importantes de la crisis inmobiliaria en los espacios precarizados son los desahucios. Descifrar las lógicas espacio-temporales de este fenómeno y cartografiar las consecuencias socio-espaciales a diferentes escalas en Menorca es la finalidad en los siguientes apartados.

\section{Metodología y fuentes}

Esta investigación pretende avanzar en los estudios urbanos de Menorca y en el análisis de una problemática que cada vez tiene más relevancia social y que todavía no ha sido suficientemente incluida dentro del estudio de las dinámicas metropolitanas en España.

Por tanto, como se ha expuesto, el principal objetivo es analizar y cartografiar las ejecuciones hipotecarias en el marco de la realidad socio-urbana menorquina. Para ello, se plantea en primer lugar elaborar un análisis de los diferentes categorías sociales de la isla y cartografiarlas; en segundo lugar, analizar la distribución espacial de las ejecuciones hipotecarias; y en tercer lugar superponer y analizar conjuntamente ambas cuestiones para aportar un mejor entendimiento de las raíces socio-urbana de la desposesión de vivienda en Menorca. De esta manera, la metodología seguida permite estudiar la relación existente entre el rango social y la densidad de desposesión de vivienda a escala intraurbana.

A continuación se exponen las metodologías utilizadas tanto para elaborar la cartografía social como para la cartografía de las ejecuciones hipotecarias.

\section{Metodología para el mapa social de Menorca}

No son muchos los trabajos que han estudiado los aspectos relacionados con la precarización social en las Islas Baleares a escala de zonas estadísticas ${ }^{36}$ o de sección

35 Baulies, 1964-1967; Capel y Tatjer, 1975; Domènech et al, 1983; Dubon, 1987, 1993; Marí, 1991; Casasnovas, 1998, 2005; Camps, 2000; Vidal, 2001; López y Rosselló, 2002; Vilardell, 2005; Artigues et al, 2006; Murray, 2006

36 Carbonero et al., 2002. 
censal ${ }^{37}$. Para este estudio se ha adoptado la metodología implementada por Rubiales, Bayona y Pujadas ${ }^{38}$ para el caso de Madrid, a escala de sección censal con datos del Censo de Población y Vivienda de 2001. El análisis social se lleva a cabo mediante la realización de un análisis multivariado que aplica análisis de componentes principales y de clúster a escala de sección censal. El conjunto de datos de cada una de las secciones censales tienen la siguiente información sobre las viviendas y la población: (i) extranjeros, (ii) empleos de categoría alta, media-alta, media-baja y baja, (iii) cuatro grados de estudios (desde "sin educación" a "educación universitaria"), (iv) emprendedores, pequeños propietarios y trabajadores; y (v) porcentaje de viviendas de menos de $70 \mathrm{~m}^{2}$, entre 70 y $120 \mathrm{~m}^{2} \mathrm{y}$, más de $120 \mathrm{~m}^{2}$.

En el análisis de componentes principales, aplicando el método de rotación Varimax, las variables iniciales se reducen a pocos factores para eliminar las redundancias y estandarizar los valores. Los dos principales componentes principales del estudio representan el $63 \%$ de la varianza total y fueron identificados, uno de ellos, como las de estatus social medio-alto y el otro como de estatus bajo. Posteriormente, se realizó un análisis clúster jerárquico sobre los dos factores antes mencionados utilizando el método de Ward (distancia euclidiana) y el número inicial de los grupos se estableció en tres. A través de esta técnica se asignaron las secciones censales a uno de los tres grandes grupos de acuerdo con los valores que presentan:1) estatus social medio-alto; 2) estatus social bajo; 3 ) estatus social mixto. No encontramos, por tanto, entre tres tipos de secciones atendiendo a las variables citadas referidas a origen, empleo, estudios y vivienda. Secciones de mayor categoría social donde residen las clases sociales alta y media, en el otro extremo las secciones de categoría social baja donde se localizarían las clases sociales bajas, entre y entre un grupo importante de secciones donde se entremezclan todo tipo residentes, son las llamadas secciones mixtas.

Al tratarse de un análisis a partir de censo de población y viviendas debe tenerse en cuenta que queda fuera del estudio la población no residente. Esta circunstancia, si no se tiene en cuenta, puede llevar a confusión al analizar el mapa resultante del análisis, en especial en la costa dono la población no residente es muy importante.

\section{Metodología per cartografiar les ejecuciones hipotecarias en Menorca}

Actualmente no existe una metodología concreta para la representación territorial de las ejecuciones hipotecarias por, como ya hemos comentado, la enorme complejidad de acceso a los datos estadísticos judiciales con resolución más detallada que el partido judicial provenientes del Consejo General del Poder Judicial (CGPJ). Sin embargo, para la elaboración de un análisis urbano como el que propone este trabajo se necesita una escala detallada y la incorporación de la variable temporal.

La metodología utilizada se basa en el vaciado y explotación de datos recogidos

37 Vives-Miró, 2013.

38 Rubiales, Bayona y Pujadas, 2013. 
de los edictos en los Juzgados de Primera Instancia de Ciutadella y Maó. Con el fin de desagregar la información a escala intraurbana se han inventariado las ejecuciones hipotecarias de los juzgados número 1 y 3 de Maó y 2 de Ciutadella desde 2003 hasta 2012. En el caso de estos juzgados de Maó el inventario se ha podido realizar con resolución de dirección postal, de modo que hemos podido elaborar una cartografía de puntos muy detallada. No obstante, en el caso del juzgado número 2 de Ciutadella sólo se nos ha permitido llegar a la información a escala de núcleo urbano o urbanización. En el caso del juzgado número 2 de Maó y número 1 de Ciutadella se nos ha negado el acceso a los datos. El resultado es una base de datos que contiene estas ejecuciones hipotecarias con la dirección (calle y número / o núcleo-urbanización) y la fecha. Una vez elaborada la base de datos, se ha depurado y se tratado estadísticamente. Finalmente, a través de un Sistema de Información Geográfica se ha generado la cartografía de la distribución espacial de las ejecuciones.

\section{La realidad social de Menorca a escala de sección censal}

En este apartado del texto se aborda el análisis social de Menorca en 2001, la realidad social sobre la que se estaba hinchando la burbuja inmobiliaria que estallaría en 2007. La figura 3 cartografía la distribución espacial de las categorías sociales que se han analizado a partir de la metodología expuesta más arriba y que ya habíamos explicado y utilizado en otro trabajo referido al partido judicial de Palma ${ }^{39}$.

De acuerdo con el análisis de esta cartografía, referida a los diferentes estatus sociales de Menorca, se pueden observar diferentes aspectos que afloran también a diferentes escalas.

En primer lugar, se da una diferencia clara en función de si estamos ante ciudades, pueblos de interior o zonas turísticas. El mapa social de las zonas rurales, como también hemos podido observar en el resto zonas rurales de las islas Baleares, presenta una mayor homogeneidad con un alto grado de mixtura entre las diferentes categorías sociales. Se trata de secciones censales donde convive población de estatus social dispar, donde la segregación más propia de los centros urbanos más consolidados, no es, todavía, la norma. Por otro lado, en los dos principales núcleos urbanos de Menorca y sus entornos urbanos más próximos, Maó y Ciutadella, presentan una marcada heterogeneidad de secciones censales entre las de estatus social medio-alto y bajo. En cualquier caso esta heterogeneidad es más acusada en el caso de Maó que en el de Ciutadella donde en la parte urbana no costera, como en los pueblos, se mezclas las diferentes categorías sociales. La antigua capital menorquina, Ciutadella, conserva algunos rasgos sociales rurales que en el caso de la moderna capital burguesa, Maó, han desaparecido completamente.

En segundo lugar, el mapa social de Menorca presenta una serie de patrones que conviene destacar:

39 Vives-Miró, González y Rullan, 2015. 


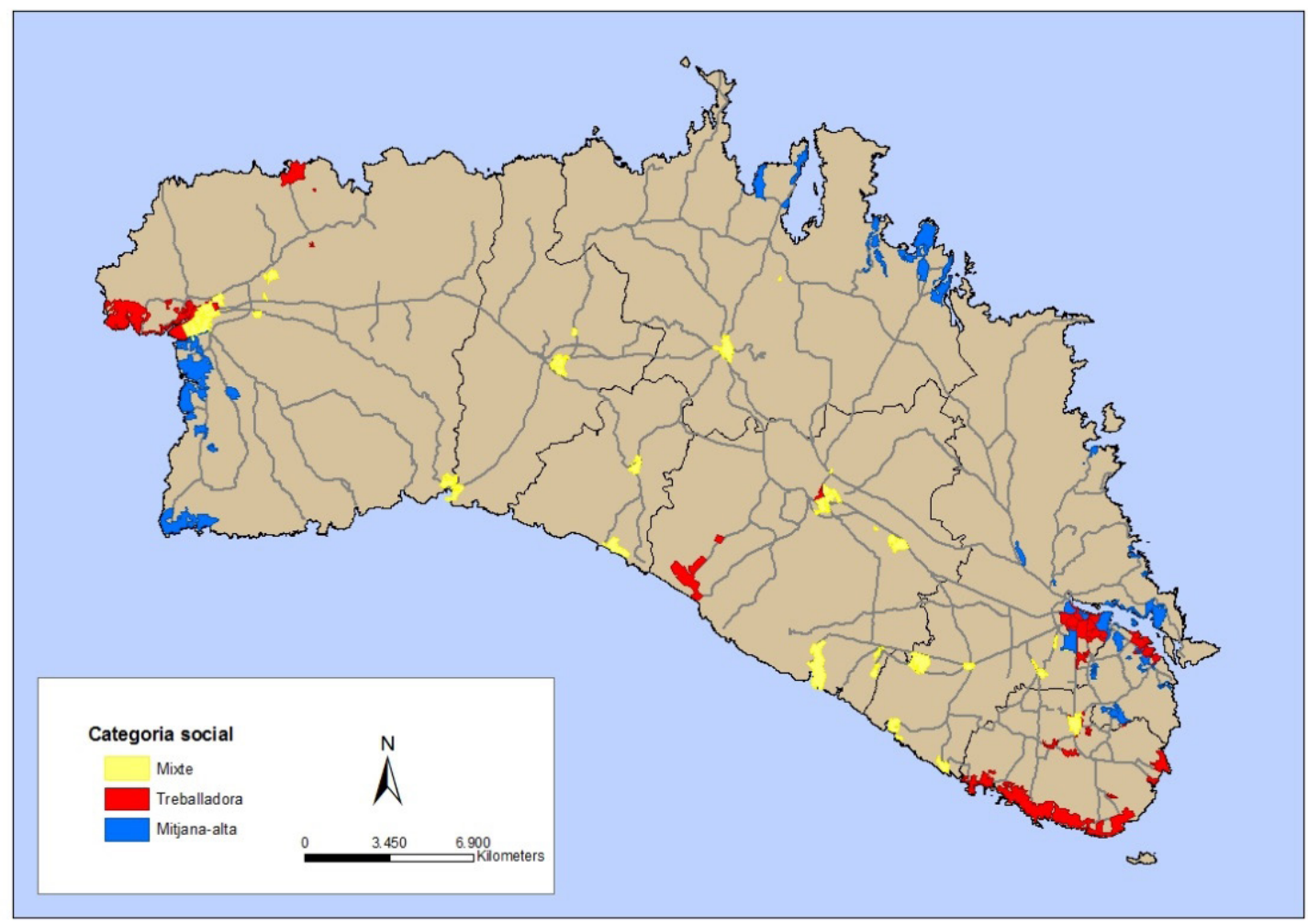

Figura 3. Estatus social de Menorca (2001)

Fuente, Elaboración propia a partir de datos del Censo de Población y Vivienda de 2001

a) los núcleos rurales interiores y, en menor medida, los del sur de la isla, son espacios donde la mixtura entre secciones censales de estatus social mixto es más presente.

b) las secciones de estatus medio-alto se localizan preferentemente en el norte turístico-residencial menorquín (Fornells, Arenal d'en Castell, Port d'Addaia, Son Parc...), y en determinados enclaves del entorno urbano de Maó y del sur residencial de Ciutadella.

c) las secciones censales de estatus social bajo son mayoritarias en las zonas centrales urbanas de Maó y Ciutadella y en el continuo urbano-turístico del sureste (s'Algar, Alcaufar, Punta Prima, Marina de Son Ganxo, Binibéquer, Binisafúller, Capd'en Font...). Hay que recordar que el análisis, al partir de los datos demográficos del INE, sólo contabiliza la población empadronada y, consecuentemente, no refleja la presencia de población turística o vinculada a segundas residencias.

d) las zonas turísticas del área de influencia de Ciutadella situadas al sur de la ciudad son de estatus social medio-alto a diferencia de las más centrales y norteñas.

Finalmente, en tercer lugar, vale la pena concretar el análisis a escala urbana de Maó y Ciutadella que, como ya hemos apuntado, es donde la heterogeneidad social de las secciones censales es mayor.

En Maó, las secciones censales de estatus medio-alto predominan en el centro 
histórico, en los barrios de Dalt de Sant Joan y plaza Eivissa, Malbúger y Fort de l'Eau. También son presentes este tipo de secciones en las zonas de Son Vilar, Trebalúger y las urbanizaciones que se despliegan a lo largo dedo el puerto, sobre todo del norte (Cala Llonga), así como se Murtar. Sin embargo, en es Castell, así como en las áreas de expansión del recinto de Maó ( siglos XX-XXI) predominan las secciones de estatus social bajo.

En cuanto Ciutadella, presenta una clara dicotomía norte-sur. Las áreas turístico-residenciales del norte son de estatus social bajo (Cala'n Blanes, los Delfines, Cales Piques, Cala Morell) mientras que en las áreas también turístico-residenciales del sur predominan las secciones de categoría social media-alta (Santandria, sa Caleta, Son Carrió, Cala Blanca, Cap d'Artrutx y Son Xoriguer). Gran parte de la ciudad consolidada de Ciutadella es de estatus social bajo, aunque la zona del ensanche mezcla todavía todo tipo de residentes, es decir, sería la zona con características sociodemográficas que más recuerda los pueblos rurales del interior.

En definitiva el mapa social de Menorca muestra la estructural sociodemográfica sobre la que se desplegará la política inmobiliaria de la burbuja y la su posterior estallido que desembocará en la crisis urbana actual.

\section{Los efectos de la crisis en Menorca: las ejecuciones hipotecarias}

Antes de entrar a analizar las ejecuciones hipotecarias, se ha estudiado la distribución geográfica de las viviendas hipotecadas en Menorca, el terreno sobre el que se podrá desplegar la oleada de ejecuciones hipotecarias. En los dos mapas resultantes (figuras 4 y 7) se ha optado por la representación de valores absolutos con el objetivo de destacar las dimensiones del fenómeno, incluido su potencial impacto en el aumento de la vulnerabilidad urbana. Aunque las cifras no sean muy elevadas, sobre todo si lo comparamos con otros partidos judiciales de mediterráneo turístico peninsular, hay importantes tasas de crecimiento interanual. En este sentido, la gravedad del fenómeno podría quedar minimizada (sobre todo las ejecuciones) si se utilizan exclusivamente en términos relativos, sea densidad de ejecuciones por habitantes o en relación al número de viviendas.

La figura 4 muestra la distribución de las viviendas hipotecadas en 2001. Las áreas urbanas con más hipotecas eran las de las urbanizaciones de Ciutadella, tanto las del sur ( Santandria, sa Caleta, Son Carrió, Cala Blanca, Cap d'Artrutx y Son Xoriguer) como las del norte (Cala en Blanes, los Delfines, calas Piques, Cala Morell). A pesar de presentar números equivalentes en cuanto a número de hipotecas (entre 600 y 1000 viviendas hipotecadas por sección censal), como se ha expuesto anteriormente, las urbanizaciones del norte están habitadas por población de estatus social bajo, mientras que las del sur por población de estatus medio-alto.

Por otra parte, la figura 5 deja ver que si bien en plena burbuja inmobiliaria anualmente se constituían unas 4.200 hipotecas (con un importe de más de 600 mi- 
llones de euros), en 2008 ya sólo fueron unas 1800 (260 millones de euros) y, a partir de entonces, las cifras han ido variando hasta las 550 en 2014 por un importe de tan solo 40 millones de euros. Como ya hemos comentado en la introducción, como en toda España, la correlación ha sido directa entre crédito a la vivienda y ejecuciones hipotecarias.

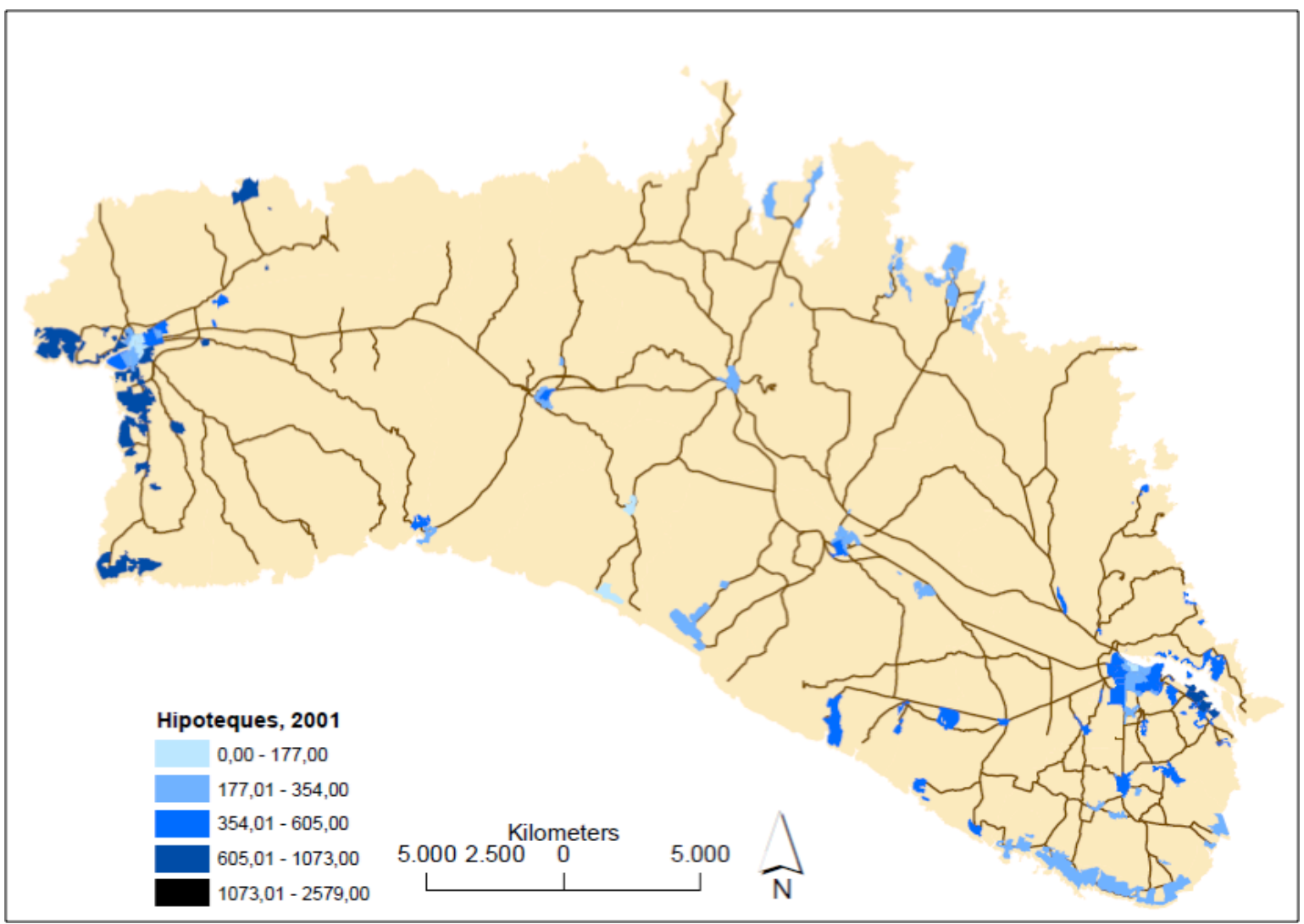

Figura 4. Viviendas hipotecados por sección censal, 2001

Fuente: elaboración propia a partir del Censo de Población y Vivienda2001

Ciutadella no es sólo el municipio más extenso de la isla sino que tiene el centro histórico turistizado y en proceso de gentrificación, áreas residenciales-turísticos de alto nivel económico, territorios turísticos maduros y espacios de reproducción social del turismo, áreas de crecimiento urbano de los siglos XX y XXI habitado por clases medias y trabajadoras, etc. Como ejemplo, un total de 89 ejecuciones hipotecarias de Ciutadella se produjeron fuera del núcleo urbano principal, destacando 15 en Son Carrió, 16 en Cala Piques y 14 en Los Delfines. Precisamente estos dos últimos se corresponden con áreas de mayoría de población trabajadora. Aunque es necesario seguir trabajando en este tema, se entiende que los casos del sur de Ciutadella son viviendas de segunda residencia no siempre propiedad de población menorquina. 


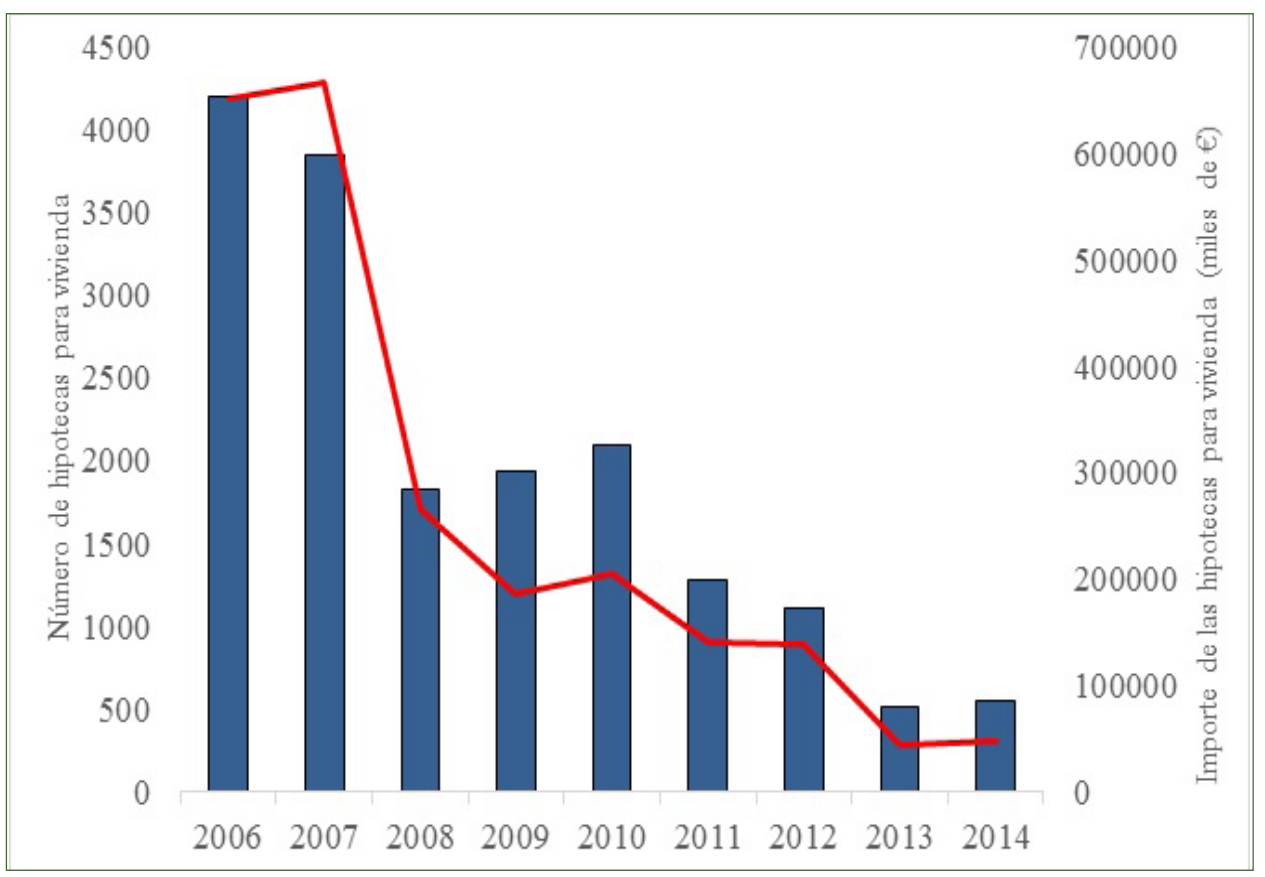

Figura 5. Constitución de hipotecas para viviendas y su importe en Menorca, 2006-2014 (Número de hipotecas en barras e importe en línea) Fuente: elaboración propia a partir de IBESTAT

Por otra parte Maó, menos extenso y de hábitat más concentrado que Ciutadella, concentra las ejecuciones en el núcleo urbano principal, con la excepción de 15 en Cala'n Porter.

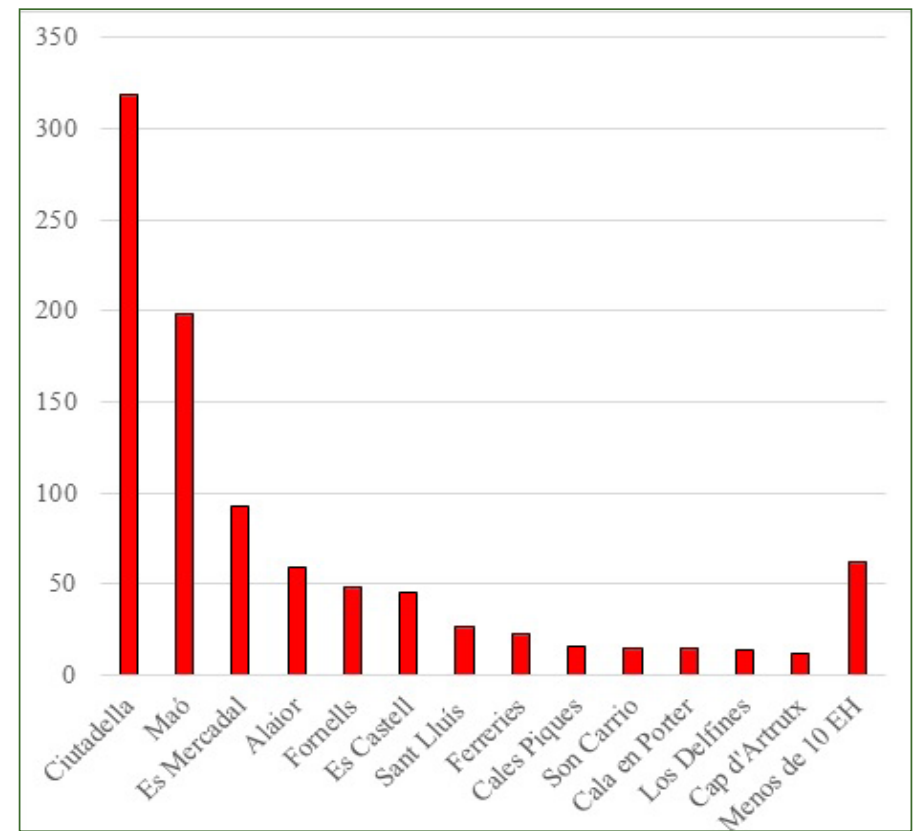

Figura 6. Total de ejecuciones hipotecarias por núcleo urbano (2003-2012) Fuente: elaboración propia 


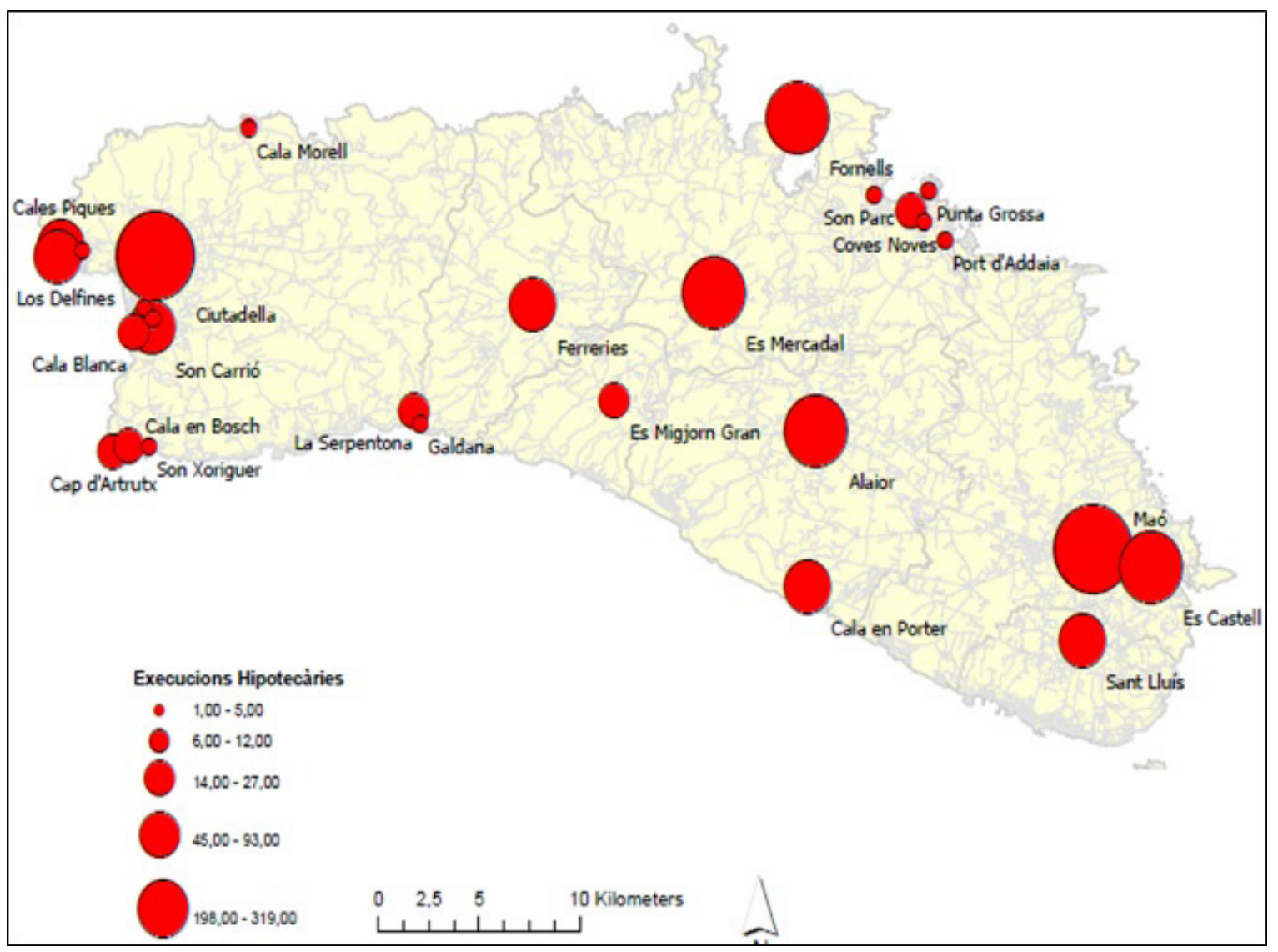

Figura 7. Localización de ejecuciones hipotecarias por núcleo urbano Fuente: elaboración propia

En el caso de las zonas urbanizadas costeras, aunque no es posible definir un único modelo de comportamiento, las ejecuciones hipotecarias tienen más presencia en las zonas turístico-residenciales que en las turístico-hoteleras. El dato denota la relevancia de las ejecuciones hipotecarias para segundas residencias.

En definitiva, la localización de las ejecuciones hipotecarias dibuja un mapa que apunta lo siguiente:

1) Aunque todo el territorio se ha visto afectado por las ejecuciones hipotecarias, en las ciudades se concentran la mayoría, ya que son espacios de mayor diversidad y segregación social.

2) Ciutadella, el municipio más extenso y con diversas morfologías urbanas, ha conocido el mayor número de ejecuciones.

3) Los casos de ejecuciones en los territorios costeros, en su mayoría, representan ejecuciones de segundas residencias.

Gracias a la localización a escala de dirección postal de las ejecuciones hipotecarias de los juzgados en los que hemos tenido acceso a esta información, estas se han podido superponer a la distribución espacial de las categorías sociales antes analizadas. De esta relación entre desposesión de vivienda y categoría social en Menorca 
se pueden extraer algunos datos de interés. El cuadro número 1 muestra el resultado en los municipios del partido judicial de Maó. El hecho de no poder acceder a la información territorializada por dirección postal en el partido judicial de Ciutadella impide realizar esta operación, que vincula ejecuciones hipotecarias y categorías sociales, en los municipios de este partido judicial. En este sentido, es necesario tener en cuenta que la metodología para elaborar los mapas sociales se elabora a escala de sección censal, y en Ciutadella sólo tenemos datos de ejecuciones a nivel de núcleos.

\begin{tabular}{|c|c|c|c|c|c|c|c|c|}
\hline & \multicolumn{5}{|c|}{ Números Absolutos } & \multicolumn{2}{|c|}{$\%$} & \multirow[b]{2}{*}{ Total } \\
\hline & Mixto & Baja & Media-alta & Total & Mixto & Baja & Media-alta & \\
\hline Alaior & 32 & 4 & 0 & 36 & 88,89 & 11,11 & 0,00 & 100 \\
\hline Es Castell & 0 & 34 & 30 & 64 & 0,00 & 53,13 & 46,88 & 100 \\
\hline Maó & 9 & 172 & 150 & 331 & 2,72 & 51,96 & 45,32 & 100 \\
\hline Sant Lluís & 11 & 18 & 0 & 29 & 37,93 & 62,07 & 0,00 & 100 \\
\hline TOTAL & 52 & 228 & 180 & 460 & 11,30 & 49,57 & 39,13 & 100 \\
\hline
\end{tabular}

Cuadro 1. Ejecuciones hipotecarias por categorías sociales en el partido judicial de Maó.

Fuente: elaboración propia a partir de los datos de los Juzgados de Mahón y del INE

En este sentido, se observa que en números absolutos (del muestreo recogido) el $49,5 \%$ de las ejecuciones se sitúan en zonas de estatus social bajo, el 39\% en las zonas de clases medias-altas y tan sólo el $11 \%$ en secciones mixtas. Por tanto, una primera conclusión que se puede adelantar es que las ejecuciones han tenido lugar mayoritariamente en las áreas más precarizadas y que allí donde no hay segregación social o donde hay menos, como en los núcleos más rurales, es donde se ejecutan menos hipotecas. Las ejecuciones allí donde reside la población de categoría social media-alta, también son importantes (39\%) e imputables a ejecuciones sobre nuevas promociones tanto de primera como de segunda residencia.

\section{Localización de las ejecuciones hipotecarias en el interior de la ciudad. El caso de Maó}

Con los datos procedentes de los juzgados 1 y 3 de $\mathrm{Maó}^{40}$ hemos podido analizar a escala intraurbana lo que hasta ahora hemos visto a escala territorial.

El volumen de desahucios y su distribución territorial son una expresión de la ciudad desigual y un indicador de los riesgos de vulnerabilidad. Por un lado, los im-

40 Como ya se ha apuntado las secretarías del juzgado número 2 de Maó y del número 1 de Ciutadella no nos han facilitado los datos y el juzgado número 2 de Ciutadella sólo nos los ha facilitado a escala de núcleo de población, sin desagregar a nivel de calle y número. Aun así los resultados localizados a escala de dirección postal referidos a Maó que analizamos ahora representan una más que significativa muestra del $66 \%$. 
pactos de la crisis son también una consecuencia de los procesos iniciados antes de la recesión. Así, los desahucios se deben entender en el contexto del previo sobreendeudamiento familiar ${ }^{41}$ que, entre otros, conllevó la creación de una burbuja hipotecaria. Por otro, las débiles estructuras sociales sobre las que se fundamenta la ciudad española la exponen con relativa facilidad a las amenazas surgidas en períodos de crisis. Según la clasificación de Esping-Andersen ${ }^{42}$, España participa de muchos de los rasgos del modelo de Estado de bienestar corporatista. Según este, se conservan las diferencias de estatus social, ya que los derechos sociales están vinculados a la clase y al estatus ${ }^{43}$. Así, unas insuficientes políticas sociales y de protección hacen depender a la sociedad únicamente de la hipotética seguridad que proporciona el empleo. Ante la falta de este, el sistema se desmorona. Y esto es lo que observamos en nuestro caso de estudio. La evolución comparativa del número de parados y de ejecuciones hipotecarias en Maó es una muestra de los estrechos vínculos entre las dos variables. La evolución de las ejecuciones tiene una mayor variabilidad. El aumento del paro antecede uno o dos años al incremento del número de desahucios (Figura 8).

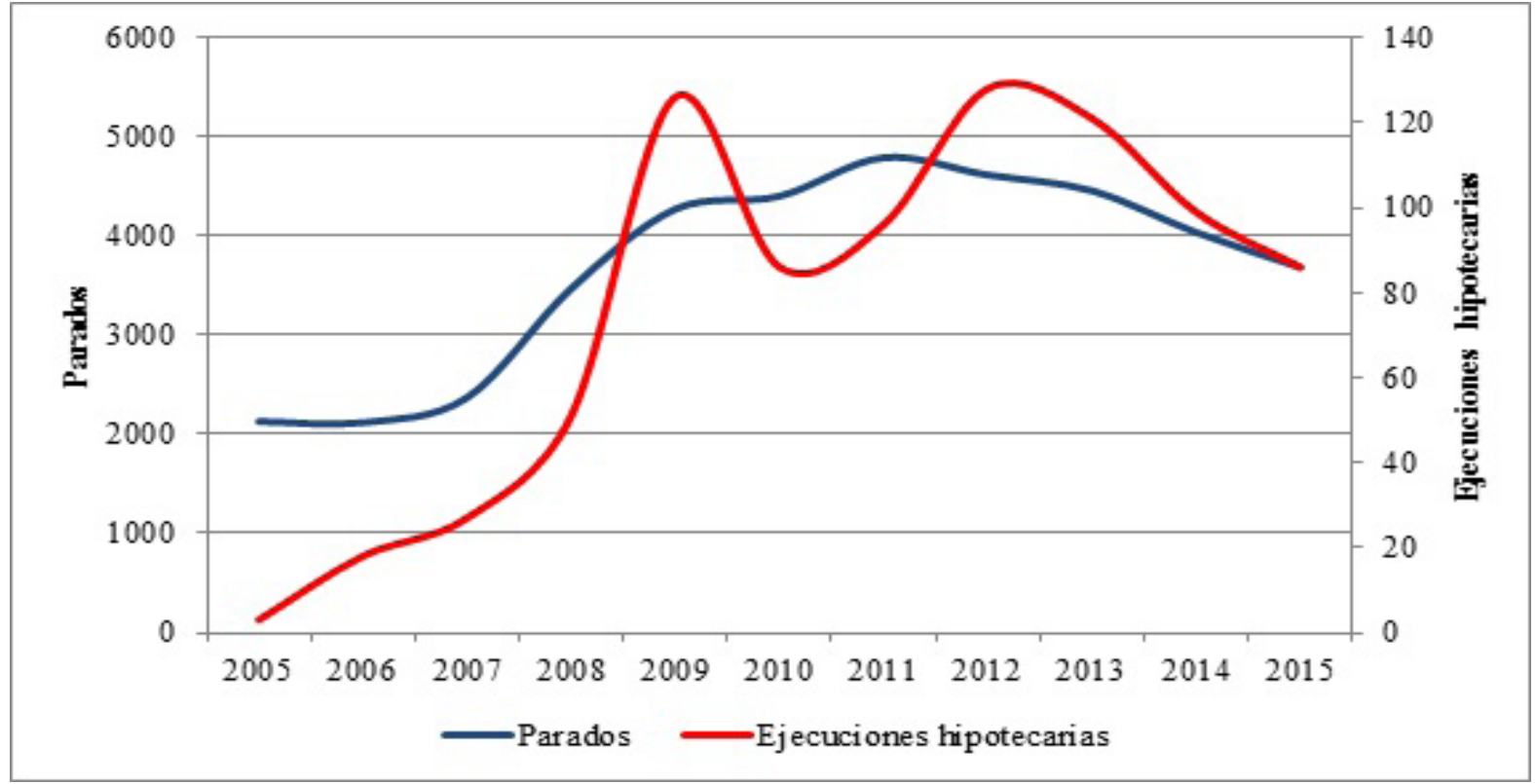

Figura 8. Evolución del número de parados y ejecuciones hipotecarias en el partido judicial de Maó (2005-2015)

Fuente: elaboración propia a partir de estadísticas judiciales e IBESTAT con datos del Servei d'Ocupació de les Illes Balears (SOIB)

La localización del fenómeno se refleja claramente con los datos acumulados en dos períodos: 2003-2007 (burbuja inmobiliaria y etapa de bonanza económica) y 2008-2013 (explosión de la burbuja y período de crisis). Esta georreferenciación

41 Gutiérrez y Delclós, 2015.

42 Esping-Andersen, 1993.

43 Ochando, 2002. 
de los datos lo superponemos sobre el mapa social de 2001, por ser este uno de los años de referencia de la burbuja inmobiliaria. El 94,18\% de las ejecuciones hipotecarias se han producido en los últimos seis años, hecho que confirma el impacto de la crisis y la desposesión de la vivienda. Coincidiendo con los datos analizados en el apartados anterior (cuadro, 1), en los dos períodos los resultados más negativos se obtienen en las zonas clasificadas como lugar de residencia de población de estatus social más bajo, lo que constata la relación entre espacios más vulnerables y desahucios, especialmente durante el periodo 2008-2013 de crisis (cuadro 2).

\begin{tabular}{|l|c|l|c|}
\hline & Medias-altas & Mixtas & Trabajadoras \\
\hline EH 2003-2007 & 2 & 2 & 6 \\
\hline EH 2008-2013 & 48 & 7 & 84 \\
\hline
\end{tabular}

Cuadro 2. Distribución de las ejecuciones hipotecarias según estatus social y período Fuente: elaboración propia a partir de estadísticas Juzgados Primera Instancia de Maó

El municipio de Maó es el menos extenso de Menorca y predominan formas urbanas compactas con continuidad espacial. Los crecimientos más recientes son desarrollos residenciales e industriales periféricos a la ciudad, en contacto con la vía de circunvalación y las carreteras que se dirigen a Sant Lluís, Sant Climent y es Castell. La suburbanización se expande hacia municipios vecinos, sobre todo aquellos turísticos y litorales. Una primera lectura de la figura 9 la dicotomía entre secciones de población de categoría media-alta y baja en Maó. Las primeras se localizan en la antigua ciudad intramuros, el área turístico-residencial predominantemente de baja densidad que se extiende por el litoral norte de la bahía, así como desarrollos urbanos recientes, entre los que destacan los barrios localizados en los dos extremos del paseo marítimo, Son Vilar y Malbúrger. Este último caso ha adquirido una destacada centralidad en la actualidad después de la localización de importantes edificios administrativos de influencia insular (sede del Consell Insular de Menorca Oficina de Ocupación, Hospital Mateu Orfila, Prefectura de Tránsito de Menorca...) y urbanizaciones de viviendas para clases medias (González, en prensa). Mientras tanto, la ciudad de la clase trabajadora se localiza en barrios históricos del XVII-XIX, incluido el ensanche de población. En los otros municipios del partido judicial, como corresponde a núcleos con mayor componente rural, la homogeneidad social es más importante. Aunque las clases sociales medias y altas ocupan Trebelúger y algunos crecimientos periféricos de es Castell, el núcleo urbano de Sant Lluís es mixto y, a pesar de su riqueza patrimonial y apariencia turística, las clases trabajadoras predominan en es Castell.

Utilizando como base este mapa social, el $60,40 \%$ de las ejecuciones hipotecarias $^{44}$ se localizan en áreas de estatus social bajo, destacando la concentración en dos barrios de Maó: Tanques del Carme (ensanche de 1811 con trazado ortogonal) 44 Ver nota 41. 
y el camí de ses Vinyes (urbanización, en ocasiones irregular, producto del desarrollismo de las décadas de 1960-70). Las ejecuciones en barrios de clases medias-altas $(33,55 \%)$ se producen fundamentalmente en el centro histórico, Fort de l'Eau y Malbúguer. Los asentamientos del norte de la bahía, área de alto nivel económico, suman una sola ejecución hipotecaria. El 3,30\% de desahucios se han producido en la única zona definida socialmente como mixta, que coincide con la mayor parte del núcleo de Sant Lluís.

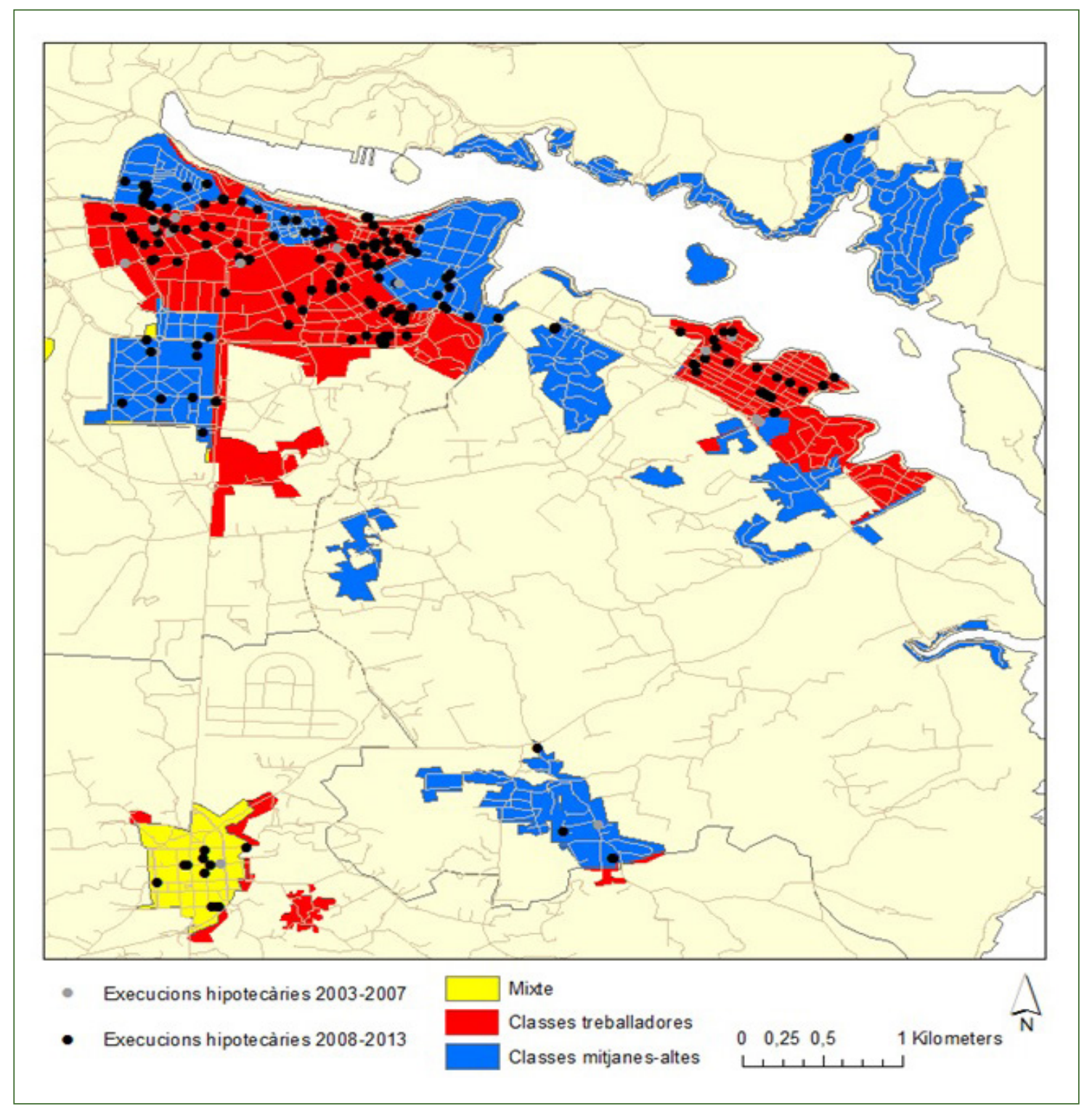

Figura 9. Ejecuciones hipotecarias por categorías sociales en el partido judicial de Maó Fuente: elaboración propia a partir de datos de los juzgados número 1 y 3 de Maó.

Para cerrar el apartado, hemos analizado y los principales ejecutores hipotecarios del partido judicial de Maó (cuadro 3) y mapificado sus ejecuciones en la ciudad de Maó (figura 10). Una información que habitualmente no es estudiada debido a la dificultad de acceso a los datos. Aparentemente no hay un patrón claro de distribu- 
ción, debido a que el crédito bancario es con frecuencia otorgado por entidades con implantación en el barrio o el núcleo urbano. Aunque es esta variable la que explica la mayor o menor representación de una determinada entidad financiera, se detectan pequeñas concentraciones. Por ejemplo, La Caixa ha ejecutado más en el este trabajador de Maó y BBVA en el oeste de clases-medias altas de esta misma ciudad. Asimismo, antiguas cajas de ahorros, una catalana (La Caixa) y otra originalmente balear (Sa Nostra - Banco Mare Nostrum), son los principales ejecutores. Le siguen en importancia bancos de implantación internacional, como BBVA y Santander, seguido de la Caja de Ahorros del Mediterráneo (CAM). Además, hay un número importante de ejecutores que no son entidades financieras. Entre otros, son los casos de Fincas Moure-Moher, Keyges, Rubriget, General de Hostelería y Restauración y fundamentalmente Unión de Créditos Inmobiliarios e Isba - Sociedad de Garantía Recíproca.

\begin{tabular}{|c|c|c|c|c|c|c|c|c|c|}
\hline \multirow[b]{2}{*}{ Entidades financieras } & \multicolumn{2}{|c|}{ Maó } & \multicolumn{2}{|c|}{ Alaior } & \multicolumn{2}{|c|}{ Es Castell } & \multicolumn{2}{|c|}{ Sant Lluís } & \multirow{2}{*}{$\frac{\text { Total }}{2003-13}$} \\
\hline & $2003-7$ & $2008-13$ & $2003-7$ & $2008-13$ & 2003-7 & $2008-13$ & 2003-7 & $2008-13$ & \\
\hline Banca March & 1 & 1 & 1 & 5 & 0 & 0 & 0 & 0 & 8 \\
\hline Crèdit Balear/Popular & 0 & 4 & 1 & 3 & 0 & 1 & 0 & 0 & 9 \\
\hline BBVA & 0 & 16 & 1 & 3 & 0 & 2 & 0 & 6 & 28 \\
\hline CAM & 2 & 2 & 1 & 8 & 1 & 3 & 0 & 0 & 17 \\
\hline Santander & 0 & 7 & 1 & 8 & 0 & 4 & 0 & 1 & 21 \\
\hline La Caixa & 2 & 36 & 0 & 7 & 1 & 14 & 1 & 5 & 66 \\
\hline Sa Nostra/BMN & 0 & 29 & 0 & 11 & 0 & 2 & 0 & 3 & 45 \\
\hline Barclays & 0 & 3 & 0 & 4 & 0 & 0 & 0 & 0 & 7 \\
\hline Bankinter & 2 & 3 & 0 & 0 & 1 & 3 & 0 & 2 & 11 \\
\hline Bankia & 0 & 1 & 0 & 0 & 0 & 2 & 0 & 0 & 3 \\
\hline Otros & 5 & 17 & 2 & 3 & 1 & 8 & 1 & 8 & 45 \\
\hline
\end{tabular}

Cuadro 3. Principales ejecutores hipotecarios en los municipios del partido judicial de Maó entre 2003 y 2013

Fuente: elaboración propia a partir de los datos de los Juzgados número 1 y 3 de Maó

Frente a la gravedad de las ejecuciones hipotecarias y las evidencias de empobrecimiento urbano y expansión territorial de la vulnerabilidad, ayuntamientos como los de Madrid y Barcelona están ejecutando importantes acciones de paralización de desahucios, realojos sociales y otro tipo de soluciones que buscan priorizar el derecho a la ciudad. Entre otras muchas acciones, Madrid creó una oficina anti-desahucios (Oficina de Intermediación Hipotecaria) y Barcelona la Unitat Contra l’Exclusió Residencial (UCER) (González, Lois y Piñeira, en prensa). 


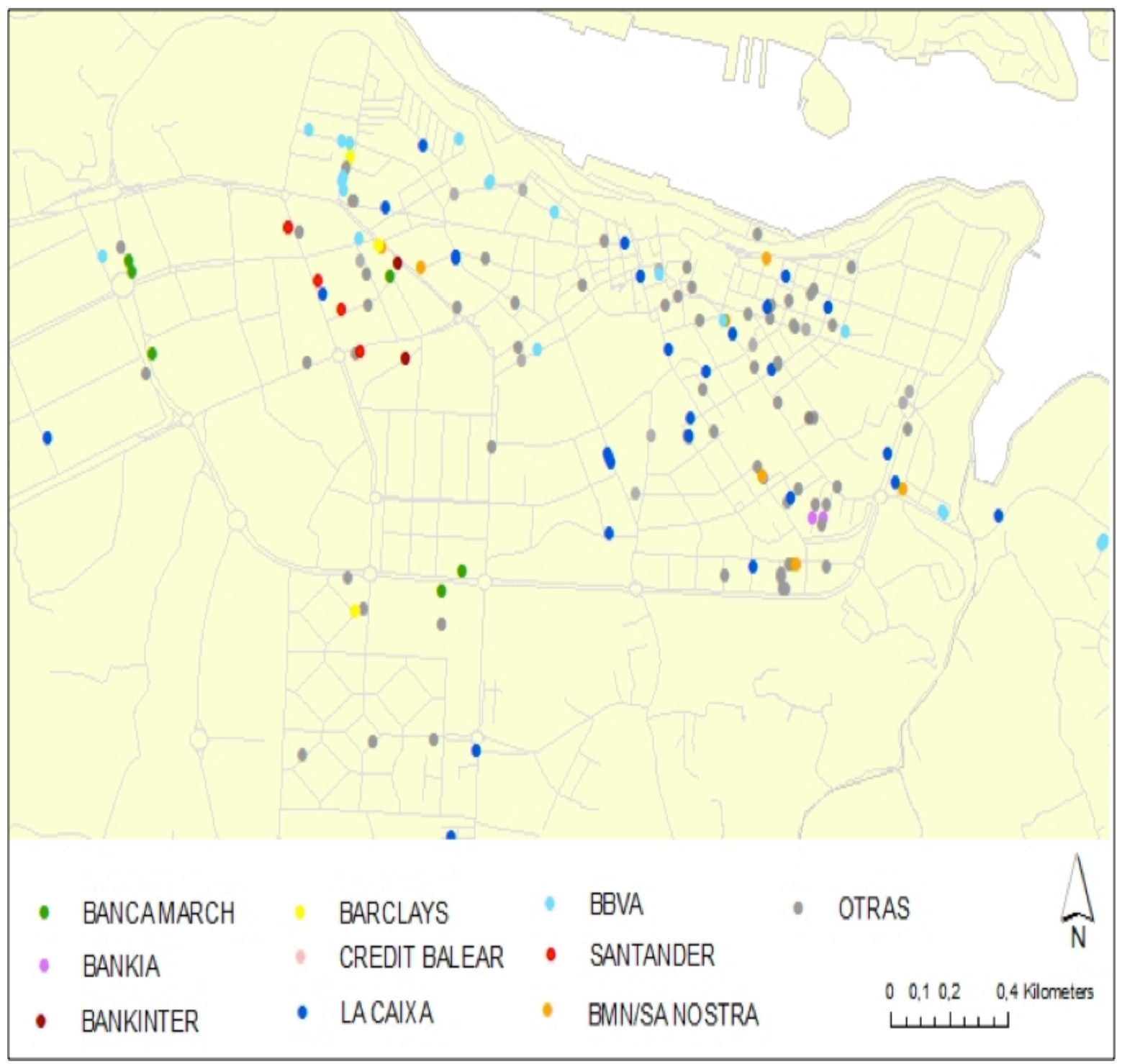

Figura 10. Ejecuciones hipotecarias por entidad financiera en el partido judicial de Maó Fuente: elaboración propia a partir de los datos de los Juzgados número 1 y 3 de Maó

En el marco de los nuevos modelos de ciudad proyectado por partidos políticos constituidos como resultado de plataformas ciudadanas y movimientos sociales, el ayuntamiento de Maó, liderado por el partido Ara Maó, está introduciendo también algunas medidas que pueden ayudar a reducir los impactos de los desahucios. Por un lado, se creó el Servei d'Informació Hipotecari. Sin embargo, a diferencia de las más efectivas e intervencionistas oficinas anti-desahucios de Madrid y Barcelona, este servicio maonés se centra en actuaciones básicamente de tipo informativo. Se trata de un servicio gratuito de apoyo y asesoramiento en materia de ejecuciones hipotecarias, dirigido a personas con dificultades para hacer frente al pago de los préstamos hipotecarios y que están en riesgo de perder su domicilio habitual. Por otro lado, el presupuesto de 2016 ha duplicado la partida destinada a ayudas sociales de emergencia y aumenta los servicios de la Casa de Acollida. Un total de 14,45 
millones de euros $(41 \%)$ del presupuesto están vinculados a programas y actuaciones de tipo económico y 10,15 millones (29\%) a partidas sociales y comunitarias.

\section{Conclusiones}

La literatura geográfica que aborda la vinculación entre ejecuciones hipotecarias y procesos de desposesión de vivienda entendida como un nuevo cerramiento urbano es escasa. Sin embargo los resultados y desenlace derivados del estallido de la burbuja inmobiliaria constatan como el resultado final del proceso vincula ambas cuestiones: la desposesión de la vivienda para amplias capas de la sociedad supone una nueva ronda de acumulación gobernada por las principales entidades financieras.

El ciclo económico del que venimos estuvo -y en gran parte sigue estando- basado en la revalorización inmobiliaria y el crédito como medio de mantener al alza los principales indicadores económicos. Agotado el modelo, las consecuencias de su quiebra han sacudido con especial virulencia a aquella población de menor estatus social y más vulnerable que había apostado por la vía del endeudamiento ante la imposibilidad de avanzar económica y socialmente con empleos mejor remunerados.

Las zonas con población más empobrecida/vulnerable y las que más se habían expuesto al crédito, ambas características especialmente presentes en las zonas urbanas, se han revelado como las más castigadas por los procesos de desposesión de vivienda fruto de ejecuciones hipotecarias. Por otra parte las zonas urbanas donde las diferencias de estatus social es menor, donde se da una relativa mezcla entre población de diferente categoría social, el impacto no ha sido tan acusado. El caso de estudio de Menorca matiza y corrobora lo apuntado.

La llamada crisis urbana se ha mostrado especialmente severa en las ciudades de más alto rango en la jerarquía urbana, a mayor posición competitiva en el ranquin de ciudades, mayores índices de empobrecimiento/vulnerabilidad en las zonas marginales del área de influencia directa de estas ciudades. Se escala en la jerarquía gracias a la marginalización económica y social de una parte de la población, aumentado la competitividad según la jerga neoliberal. Las zonas muy empobrecidas son la necesaria otra cara de la moneda de las muy enriquecidas. Este principio general es constatable, aunque con matices, también en Menorca donde hemos podido constatar como las dos ciudades de la isla, Maó y Ciutadella, que suman el 62\% de la población sin embargo concentran el $66 \%$ de la ejecuciones hipotecarias, una diferencia de porcentajes que, sin duda, se agrandaría si subiéramos en la jerarquía urbana y que avanzamos como hipótesis para futuras investigaciones.

En las zonas rurales de la isla la sacudida de las ejecuciones hipotecarias no ha sido tan importante pues, entre otros, el mapa social presenta una mayor heterogeneidad. La composición social mixta de sus secciones censales ha permitido 
amortiguar levemente los efectos de la crisis, los vínculos de solidaridad son más importantes en los pueblos ${ }^{45}$ que en las ciudades $y$, además, presentan una menor exposición al crédito, ambas circunstancias ayudan a explicar su relativamente menor gravedad de la crisis. Sólo la irrupción de créditos para segunda residencia, especialmente en la costa sur de Ciutadella, han expandido las ejecuciones hipotecarias más allá de las zonas centrales de la ciudad.

A escala intraurbana, estudiada para el caso del área urbana de Maó, se corroboran los mismos principios generales. Las secciones censales de estatus social bajo concentran el 50\% de las ejecuciones hipotecarias y, en el otro extremo, las secciones censales con población mixta en cuanto a estatus social sólo concentran el $11 \%$ de las mismas. Entre y entre, la secciones censales con población de estatus social medio-alto concentra el 39\% restante.

En definitiva, la mayor exposición al crédito, más propio de ciudades que de núcleos rurales, es la más importante de las variables explicativas de la geografía de las ejecuciones hipotecarias. Un principio que también se constata en Menorca donde antes de la crisis se firmaban algo más de 4000 hipotecas que, en 2013, habían descendido a algo más de 500. Por su parte, para las misma fechas, la ejecuciones hipotecarias habían aumentado de 34 a 216, la serie entera muestra un índice de correlación negativo $(-0,84)$ entre ambas variables. La mayor concentración de hipotecas se localiza en el término municipal de Ciutadella donde la apuesta inmobiliaria había sido más fuerte.

Los principales responsables de este proceso han sido las entidades financieras que inicialmente animaron a la población a la firma de hipotecas para la compra de viviendas en propiedad y, ahora, ejecutan las hipotecas y desahucian a sus ocupantes. Los principales ejecutores de las hipotecas en el partido judicial de Maó han sido, por este orden, Banco Mare Nostrum, Caixabank, BBVA, la Caixa y el Santander.

Las antiguas cajas que en su momento impulsaron el proceso, en la mayoría de casos, se hundieron y hoy pertenecen a bancos privados gracias al reciente proceso de privatización llevado a cabo con ayudas públicas. Visto en perspectiva, lo acontecido en el último ciclo expansivo/depresivo, dibuja una estrategia preconcebida que se pone claramente de manifiesto al observar los resultados: tanto las viviendas que se financiaron con hipotecas como las entidades que las suscribieron han acabado en manos de bancos privados, se ha consumado un proceso de desposesión de vivienda y de entidades financieras semiprivadas como eran las antiguas cajas de ahorros.

45 Como otros estudios han demostrado que estos vínculos son también más importantes en las ciudades del sur que en las del norte económico. 


\section{Bibliografia}

AALBERS, M. The Financialization of Home and the Mortgage Market Crisis. Competition \& Change, 2008, vol. 12, nº 2, p. 148-166.

AALBERS, M. Geographies of the financial crisis. Area, 2009a, vol. 41, nº 1, p. $34-42$.

AALBERS, M. The Sociology and Geography of Mortgage Markets: Reflections on the Financial Crisis. International Journal of Urban and Regional Research, 2009b,vol. 33, n 2, p. 281-290.

ARTIGUES, A. A. et al. Introducción a la Geografía Urbana de las Illes Balears. Palma: Universitat de les Illes Balears/AGE,2006.

BAULIES, J.L'illa de Menorca. Barcelona: Barcino. 1964-1967.

BRENNER, N. et al. Cities for People, Not for Profit: Critical Urban Theory and The Right To The City. London:Routledge,2012.

BRENNER, N. y Theodore, N. Spaces of Neoliberalism: Urban Restructuring in North America and Western Europe. Malden: Blackwell, 2002.

CAMPS, A.La història de Ciutadella de Menorca a través dels fons ceràmic del Museu Municipal de Ciutadella. Ciutadella:Ajuntament de Ciutadella,2000.

CANO, G. y ETXEZARRETA, A. La crisis de los deahucios en España: respuestas intitucionales y ciudadanas". Revista de Economía Crítica, 2014, nº 17, p. 44-57.

CANO, G. et al. From Housing Bubble to Repossessions: Spain Compared to Other West European Countries. Housing Studies, 2013, vol. 28, nº 8, p. 1197-1217.

CAPEL, H. y TATJER, M. Dos ejemplos de urbanismo dieciochesco en Menorca: San Luís y Villacarlos. InMiscel-lània Pau Vilà. Barcelona: Institut d'Estudis Catalans/Societat Catalana de Geografia, 1975, 209-214.

CASASNOVAS, M.A. L'economia menorquina en el segle XIX (1802-1914). Palma: Documenta Balear,1998.

CASASNOVAS, M.A. Història de Menorca. Palma: Ed. Moll, 2005.

CARBONERO, M. A. et al.L'espai social de l'exlusió a les Balears. Una proposta dàrees d'atenció preferent. Palma: Caixa de les Balears/Universitat de les Illes Balears,2002.

CHARNOCK, G.; PURCELL, T. y RIBERA-FUMAZ, R. The limits to capital in Spain: crisis and revolt in the european south. New York: Palgrave Macmillan, 2014.

CHRISTOPHERS, B. Revisiting the Urbanization of Capital. Annals of the Association of American Geographers, 2011, vol. 101, nº 6, p. 1347-1364.

COLAU, A. y ALEMANY, A. Vidas hipotecadas. De la burbuja inmobiliaria al derecho a la vivienda. Barcelona: Cuadrilátero de libros, 2012.

CRUMP, J et al. Cities Destroyed (Again) For Cash: Forum on the U.S. Foreclosure Crisis. Urban Geography, 2008, vol. 29, nº 8, p. 745-784. 
DEFENSOR DEL PUEBLO.Crisis económica y deudores hipotecarios: actuaciones y propuestas del defensor del Pueblo. Madrid: Defensor del Pueblo,2013.

DOMÈNECH, M. et al. La ciutat des del carrer. Anàlisi formal, funcional i simbòlic del casc antic de Maó. Maó: Ateneu de Maó/COAB/SaNostra,1983.

DUBON, $\mathrm{M}^{\mathrm{a}}$. Ll. La emigración menorquina a Argelia en la primera mitad del siglo XIX. Detección y evaluación mediante análisis demográfico directo e impacto sobre la evolución posterior de la población. Anales de Geografía de la Universidad Complutense, 1987, nº 7, p. 177-184.

DUBON, $M^{\mathrm{a}}$. Ll. Estudi de la demografia actual menorquina. Les migracions i els seus efectes sobre la població i la societat illenques. Maó: Institut Menorquí d’Estudis, 1993.

DYMSKI, G.A. Afterword: Mortgage Markets and the Urban Problematic in the Global Transition. International Journal of Urban and Regional Research, 2009, vol. 33, no 2, p. 427-442.

ESPING-ANDERSEN, G. Los tres mundos del Estado del bienestar. Valencia: Alfons El Magnànim/I.V.E.I./Generalitat Valenciana, 1993.

ETXEZARRETA, A. et al. De la burbuja inmobiliaria a las ejecuciones hipotecarias. Ciudad y Territorio. Estudios Territoriales, 2012, no 174, p. 597-613.

FIELDS, D. Contesting the financialization of urban space: community organizations and the struggle to preserve affordable rental housing in New York city. Journal of Urban Affairs, 2015, vol. 37, n², p. 144-165.

GERULL, S. Evictions Due to Rent Arrears: A Comparative Analysis of Evictions in Fourteen Countries Berlin European. Journal of Homelessness, 2014, n 137, p. 137-155.

GONZÁLEZ CEBALLOS, S. Trepando por la jerarquía urbana: nuevas formas de gobernanza neoliberal en Europa. UOC Papers, revista sobre sociedad del conocimiento, 2007, no 5, p. 6-12.

GONZÁLEZ, J.M. Urbanisme i construcció de la ciutat en les Illes Balears. Palma: Lleonard Muntaner, en prensa.

GONZÁLEZ, J. M.; LOIS, R. C. y PIÑEIRA, M. J. Economic Crisis and Vulnerability in Spanish Cities: The Challenges of Urban Governance. In 2nd International Symposium, New Metropolitan Perspectives, Reggio Calabria, en prensa.

GOTHAM, K.F. The Secondary Circuit of Capital Reconsidered: Globalization and the US Real State Sector. American Journal of Sociology, 2006, vol. 112, nº 1, p. 231-275.

GOTHAM, K.F. Creating liquidity out of spatial fixity: The secondary circuit of capital and the subprime mortgage crisis. International Journal of Urban and Regional Research, 2009, vol. 33, n 2, p. 355-371.

GUTIÉRREZ, A. y DELCLÓS, X. ¿Hipertrofia inmobiliaria? Análisis de las pautas territoriales del boom. Cuadernos Geográficos, 2015, vol. 54, nº 1, p. 283-306. 
HARVEY, D. Limits to Capital. Oxford: Blackwell Publisher Limited, 1982.

HARVEY, D. From managerialism to entrepreneurialism: the transformation of urban governance in late capitalism. Geografiska Annaler Series B: Human Geography, 1989, vol. 71, no 1, p. 3-17.

HODKINSON, S. The new urban enclosures. City: analysis of urban trends, culture, theory, policy, action, 2013, vol. 16, n 5, p. 500-518.

HUMAN RIGHTS WATCH. Sueños rotos. El impacto de la crisis española de la vivienda en grupos vulnerables.USA: Human Rights Watch, 2014.

LEES, L. Y LEY, D. Introduction to special issue on gentrification and public policy. Urban Studies, 2008, vol. 45, n 12, p. 2379-2384.

LEES, L.; SLATER, T. y WYLY, E. Gentrification. London: Routledge, 2008.

LÓPEZ, I. y RODRÍGUEZ, E. Fin de ciclo. Financiarización, territorio y sociedad de propietarios en la onda larga del capitalismo hispano (1959-2010). Madrid: Traficantes de Sueños,2010.

LÓPEZ, I. y RODRÍGUEZ, E. The spanish model. New Left Review, 201 1, nº 69, p. 5-29.

MARÍ, S. La especificidad económica de Menorca en el conjunto de las Islas Baleares. Revista de Menorca, 1991, p. 5-16.

MARX, K. La llamada acumulación originaria. In El capital. Vol. 1.1990 [1864].

MÉNDEZ, R.; ABAD, L. y PLAZA, J. Geografía de las ejecuciones hipotecàrias en España. [En linea]. Madrid: Fundación 1 de mayo, 2014. http://www.1mayo.ccoo. es/nova/files/1018/Estudio84.pdf.

MIDNIGHT NOTES COLLECTIVE Introduction to the new enclosures. [En linea]. The Commoner. http://www.commoner.org.uk/02midnight.pdf, 1990.

MOORE, M.; RODRÍGUEZ-VIVES, M. y SACA-SACA, N.N. Mortgage Markets and Foreclosure Processes in Europe and the United States. In Enoch, C. et al. From Fragmentation to Financial Integration in Europe, Washington D.C.: International Monetary Fund, 2013, 409-432.

MURRAY, I. Menorca y sus ciudades. Otra rareza menorquina en las Balears. In ARTIGUES A.A. et al. Introducción a la Geografía Urbana de las Illes Balears. Palma: Universitat de les Illes Balears/AGE, 2006, 17-75.

NAVARRO, P.A. Casas vacías, personas sin casa. El Siglo de Europa, 2012, no 971 , p. 32-38.

NEWMAN, K. Post-Industrial Widgets: Capital Flows and the Production of the Urban. International Journal of Urban and Regional Research, 2009, vol. 33, n 2, p. 314-331.

OBESO, Í. Análisis geográfico de los deshaucios en España. Ería, 2014, nº 95, p. 327-342.

OCHANDO, C. El Estado del bienestar. Barcelona: Ariel, 2002. 
PECK, J. y TICKELL, A. Neoliberalizing space. Antipode, 2002, vol. 34, $\mathrm{n}^{\circ}$ 3, p. 380-404.

KAIKA, M. y RUGGIERO, L. Land Financialization as a "lived" process: The transformation of Milan's Bicocca by Pirelli. European Urban and Regional Studies, 2013, vol. 23, no 1, p. 1-20.

KRIPPNER,G. R. The Financialization of the American Economy. Socio-Economic Review, 2005, n 3, p. 173-208.

RODRÍGUEZ, J. Las ejecuciones hipotecàrias. Un año de la ley 1/2013. Revista de Derecho Civil, 2014, vol. 1, n 3, p. 105-120.

RUBIALES, M., BAYONA, J. y PUJADAS, I. Distribución espacial de las clases altas en la región metropolitana de Madrid (2001-2011). Anales de Geografía, 2013, vol. 33, $\mathrm{n}^{\circ} 2$, p. 107-136.

RUTLAND, T. The financialization of urban redevelopment. Geography Compass, 2010, vol. 4, nº 8, p. 1167-1178.

SMITH, N. The New Urban Frontier: Gentrification and the Revanchist City. London: Routledge, 1996.

STENBERG, S., DOORN, L. y GERULL, S. Locked out in Europe: A Comparative Analysis of Evictions Due to Rent Arrears in Germany, the Netherlands and Sweden. European Journal of Homelessness, 2011, vol. 5, n 2, p. 39-61.

VALIÑO, V. Emergencia habitacional en el Estado español. La crisis de las ejecuciones hipotecarias y los desalojos desde una perspectiva de derchos humanos. Barcelona: Observatorio Plataforma de Afectados por la Hipoteca, 2013.

VIDAL, T. Fonaments geogràfics de la història (dialèctica home-territori). In Vidal Hernández, J.M. (dir) Enciclopèdia de Menorca. Tom IX. Història I: des dels inicis del poblament a l'època talaiòtica. Maó: Obra Cultural de Menorca,2001.

VILARDELL, J.E. La fundación de Georgetown, Menorca 1771. Patrick Mackellar y el urbanismo militar británico. Maó: COAB, 2005.

Vives-Miró, S.L'espai urbà del capitalisme. La construcció del projecte neoliberal de Palma. Tesis doctoral dirigida por Onofre Rullan. Palma: Universitat de les Illes Balears, 2013.

VIVES-MIRÓ, S. y RULLAN, O. La vivienda en el tránsito de la reproducción ampliada del capital a la acumulación por desposesión en España. In Territorios inconclusos y Sociedades Rotas, Madrid: Grupo de Geografía Urbana (AGE) 2014, p. 1-10.

VIVES, S.; GONZÁLEZ, J.M. y RULLAN, O. Home dispossession: uneven geography of evictions in the city of Palma (Majorca). Die Erde. Journal of the Geographical Society of Berlin, 2015, vol. 146, n²-3, p. 113-126.

WALKS, A. Mapping the Urban Debtscape: The Geography of Household Debt in Canadian Cities. Urban Geography, 2013, vol. 34, no 2, p. 153-187. 
WAINWRIGHT, T. Laying the Foundations for a Crisis: Mapping the HistoriCo-Geographical Construction of Residential Mortgage Backed Securitization in the UK. International Journal of Urban and Regional Research, 2009, vol. 33, nº 2, p. $372-388$.

(c) Copyright: Sònia Vives-Miró, Onofre Rullan, Jesús M. González Pérez, 2017

(c) Copyright Scripta Nova, 2017.

Ficha bibliográfica:

VIVES-MIRÓ, Sonia; RULLAN, Onofre; GONZÁLEZ PÉREZ, Jesús M. Consecuencias sociales del modelo económico basado en el crédito, Geografía de las ejecuciones hopotecarias en Menorca. Scripta Nova. Revista Electrónica de Geografía y Ciencias Sociales. [En línea]. Barcelona: Universidad de Barcelona, 1 de enero de 2017, vol. XXI, no 553. <http://revistes.ub.edu/index.php/ScriptaNova/article/view/553>. ISSN: $1138-9788$. 